\title{
LA OBJECIÓN DE CONCIENCIA EN EL ORDENAMIENTO JURÍDICO ESPAÑOL: ¿UN INSOLUBLE ENIGMA?
}

\author{
MANUEL ALENDA SALINAS*
}

\begin{abstract}
Resumen:
En el presente trabajo se aborda el estudio de la objeción de conciencia en el ordenamiento jurídico español, tanto en lo relativo a su problemática con carácter general (incluida la cuestión relativa a la determinación de su naturaleza jurídica); como por lo que respecta al análisis de las diferentes manifestaciones de la objeción de conciencia que tienen reconocimiento en el mismo (al servicio militar, sanitaria, farmacéutica, a formar parte de una mesa electoral y otras). Todo ello, atendiendo a la más reciente jurisprudencia del Tribunal Constitucional dictada en la materia.

Palabras clave:

Objeción de conciencia (naturaleza jurídica y clases). Libertad de creencias. Conflictos entre conciencia y ley. Resistencia al Derecho.
\end{abstract}

\begin{abstract}
:
This paper deals with the objection of conscience in the Spanish juridical order, in general terms and related to its juridical nature, studying as well what comes up from its different manifestations, like the ones on the service of arms, pharmaceutical, electoral matters, etc. Every aspect, on the other hand, is developed with the support of the more recent jurisprudence of the Spanish Constitutional Court.

KEY WORDS:

Objection of conscience -juridical nature and different types. Freedom of Beliefs. Conflicts between conscience and the law. Resistence to legal imperatives.
\end{abstract}

\section{LA OBJECIÓN DE CONCIENCIA EN GENERAL}

La objeción de conciencia, con carácter general, viene constituyendo una institución fáctica que tiene pretensiones $-y$ a veces las ha colmado en alguna de sus concretas manifestaciones- de ser una institución jurídica. De manera que la tensión entre el mundo de los hechos y el del Derecho es lo que caracteriza a esta figura que, lejos de ser de contornos claros e indiscutidos, está llena de aristas difusas, hasta el punto de que así como a nivel popular parece existir una cierta convención acerca de su significado, sin embargo, desde un punto de vista jurídico, podemos incluso plantearnos si es una "realidad" que se ha idealizado en exceso hasta el extremo de llegar a constituir un "fantasma" jurídico. Y ello al punto de que bien podría afirmarse que la teoría jurídica de la

\footnotetext{
${ }^{*}$ Catedrático de la Universidad de Alicante (España).
} 
objeción de conciencia lleva, probablemente con razón, fama de ser un insoluble enigma ${ }^{1}$, pues no escapan al estudioso del Derecho las numerosas cuestiones controvertidas que se suscitan en esta materia, que van desde la fijación misma de su delimitación conceptual hasta la de su naturaleza jurídica, pasando por su fundamentación.

A estas dificultades ha contribuido también la doctrina del Tribunal Constitucional referida a la objeción de conciencia, que ha incurrido en vacilaciones cuando no en auténticas contradicciones, ya que si bien, en un principio, llegó a afirmar que "[p]uesto que la libertad de conciencia es una concreción de la libertad ideológica que nuestra CE [Constitución española de 27 de diciembre de 1978] reconoce en el art. 16, puede afirmarse que la objeción de conciencia es un derecho reconocido explícita e implícitamente en la ordenación constitucional española"2 y que "[l]a objeción de conciencia forma parte del contenido del derecho fundamental a la libertad ideológica y religiosa reconocido en el art. 16.1 de la CE y, como ha indicado este Tribunal en diversas ocasiones, la CE es directamente aplicable, especialmente en materia de derechos fundamentales" ${ }^{\prime 3}$. Sin embargo, el propio alto Tribunal, con posterioridad a las resoluciones acabadas de citar, ha dicho, en aparente, al menos, contradicción con la doctrina anterior, con carácter expreso y categórico, que "[l]a objeción de conciencia con carácter general, es decir, el derecho a ser eximido del cumplimiento de los deberes constitucionales o legales, por resultar ese comportamiento contrario a las propias convicciones, no está reconocido, ni cabe imaginar que lo estuviera, en nuestro Derecho, o en Derecho alguno, pues significaría la negación misma de la idea de Estado"4.

Por tanto, según estas últimas aseveraciones de tan alto Tribunal la objeción de conciencia no puede tener más existencia que cuando la reconozca el propio legislador: No cabe más objeción de conciencia que la "juridificada". Esta doctrina del Tribunal Constitucional, que empieza a plasmarse con las Sentencias 160 y 161, ambas de 27 de octubre de 1987, ha devenido luego jurisprudencia firme y reiterada, de modo que cada vez que el máximo Intérprete Constitucional ha tenido que pronunciarse en materia de objeción de conciencia ha insistido en la misma: No hay más objeción de conciencia con eficacia de eximir del cumplimiento de deberes jurídicos que la que haya establecido el propio legislador. Así se

\footnotetext{
${ }^{1}$ Hacemos uso de la frase de L. DÍEZ-PICAZO (Fundamentos del Derecho civil patrimonial, vol. II, 2 ed., Tecnos, Madrid, 1986, p. 447), salvando las distancias respecto de la figura de la posesión, a la que va referida.

2 Sentencia del Tribunal Constitucional 15/1982, de 23 de abril, FJ 6. El corchete, con su contenido que pretende ser aclaratorio, es nuestro.

${ }^{3}$ Sentencia del Tribunal Constitucional 53/1985, de 11 de abril, FJ 14.

${ }^{4}$ Sentencia del Tribunal Constitucional 161/1987, de 27 de octubre.
} 
ha expresado el alto Tribunal en supuestos de objeción de conciencia fiscal ${ }^{5}$, a la realización de la prestación social sustitutoria [P.S.S.] ${ }^{6}$ del servicio militar y otras conductas omisivas manifestadas en el marco de la "insumisión"7.

Muy recientemente, el Pleno del Tribunal Constitucional ha tenido ocasión de pronunciarse, en su Sentencia de 25 de junio de 2015, sobre la denominada objeción de conciencia farmacéutica ${ }^{8}$. Se trata de una resolución controvertida que, lejos de terminar de aclarar la intelección constitucional en la materia, sigue suscitando interrogantes en la misma, llevando ínsita la discusión al respecto desde el momento en que la propia Sentencia cuenta con tres votos particulares (dos disidentes y uno concurrente, aunque este último tampoco comparte la totalidad de la ratio decidendi contenida en la fundamentación y fallo de la Sentencia), que no dejan de ser reflejo de las dificultades jurídicas que venimos apuntando y que basculan, prima facie, entre la consideración de la objeción de conciencia como formando parte del contenido esencial del derecho a la

${ }^{5}$ Providencia del Tribunal Constitucional de 28 de junio de 1990 y Auto del mismo 71/93, de 1 de marzo.

6 Sentencia del Tribunal Constitucional 321/1994, de 28 de noviembre: "como en varias ocasiones ha declarado este Tribunal (SSTC 15/1982, 101/1983, 160/1987, 1227/1988), el derecho a la libertad ideológica reconocido en el art. 16 CE no resulta suficiente para eximir a los ciudadanos por motivos de conciencia del cumplimiento de deberes legalmente establecidos, con el riesgo aparejado de relativizar los mandatos legales.

Por ello, el derecho a ser declarado exento del servicio militar no deviene directamente del ejercicio de la libertad ideológica, por más que se encuentre conectado con el mismo, sino tan sólo de que la CE en su art. 30.2 expresamente ha reconocido el derecho a la objeción de conciencia, referido únicamente al servicio militar y cuyo ejercicio supone el nacimiento del deber de cumplir la P.S.S., sistema que permite al objetor cumplir los objetivos de la norma de servir a la comunidad salvaguardando sus íntimas convicciones (STC 160/1987). No puede, por lo tanto, el recurrente justificar su negativa al cumplimiento de la PSS ni apelando a la libertad ideológica, ni mediante el ejercicio de la objeción de conciencia, derecho que la CE refiere única y exclusivamente al servicio militar."

7 Sentencias del Tribunal Constitucional 55/1996, de 28 de marzo y 88/1996, de 23 de mayo, dictadas en el ámbito de los delitos relativos a la "insumisión".

Hablar de objeción de conciencia al servicio militar en nuestro País obliga a una referencia a esa acción contestataria de la regulación legal en la materia, propugnadora de desobediencia civil hacia la misma y con pretensiones de acabar no sólo con el servicio militar obligatorio, sino incluso con la existencia del mismo Ejército, aunque sea exclusivamente profesional, cual ha sido, en nuestra historia más reciente, la de los grupos favorables a la "insumisión". Después de numerosas vicisitudes en la regulación penal de esta conducta insumisa, así como en la aplicación de la misma (se dictaron numerosas condenas a dos años cuatro meses y un día de prisión), la Ley Orgánica 3/2002, de 22 de mayo, dejó sin contenido los arts. 527 y 604 del Código Penal (por considerarlos de imposible comisión en el tiempo a que se contrae), despenalizando la conducta "insumisa" con carácter retroactivo, de manera que se revisaran las sentencias condenatorias firmes y se acordara el sobreseimiento y archivo de los procedimientos penales incoados por dichos delitos. Hemos tratado estos aspectos en estudios con mayor detalle en M. ALENDA SALINAS, El régimen penal de la P.S.S. de los objetores de conciencia, Tirant lo Blanch, Valencia, 1996 y "La doctrina penal del Tribunal Supremo en materia de insumisión" (I) y (II), en Doctrina y Jurisprudencia, 10 y 11 (2000), pp. 113 ss. y 125 ss. ${ }^{8}$ Hemos consultado la versión publicada en la web del Tribunal Constitucional. 
libertad de creencias, garantizado por el art. 16.1 de la $\mathrm{CE}^{9}$, y la necesidad de la interpositio legislatoris para que la objeción de conciencia pueda tener reconocimiento jurídico.

En nuestra opinión, el alto Tribunal, aunque no sin falta de una mayor claridad y mejor fundamentación, no ha hecho, para bien o para mal, sino mantenerse en su doctrina, tanto en la pretérita (relativa a la objeción al aborto) como en la que últimamente ha venido sosteniendo respecto a la objeción de conciencia en general. Iremos tratando de desbrozar, a lo largo de las líneas que siguen, esta doctrina jurisprudencial al albur de nuestro entendimiento de la misma.

\section{¿CUÁNDO Y PORQUÉ SURGE LA OBJECIÓN DE CONCIENCIA?}

En una primera aproximación a la materia, podemos caracterizar a la objeción de conciencia como la situación que tiene lugar cuando una persona, siguiendo los dictados de su conciencia, deja de cumplir un deber que le es jurídicamente exigible ${ }^{10}$.

Se produce, pues, esa actuación del sujeto que hemos ubicado en el plano de los hechos: Incumplimiento de un deber jurídico, aunque no un mero incumplimiento sin más, sino motivado por las genuinas convicciones de la persona incumplidora. Pero esta caracterización no resulta completa si no la ponemos en relación con la valoración que ese non facere del objetor pueda recibir por parte del Ordenamiento Jurídico. Un ejemplo quizás contribuya a dar mayor claridad a cuanto queremos expresar: Cuando durante el Régimen del General Franco, algún recluta llamado al cumplimiento del servicio militar obligatorio, se llegó a pasar hasta 12 años en la cárcel, al negarse a la realización de dicho servicio alegando razones de conciencia para ello, ¿era objetor de conciencia o no lo era? Desde el mundo de los hechos, lo era, clarísimamente. Desde el punto de vista del Derecho su negativa, su actuación fáctica, no tenía más reconocimiento jurídico que el plasmado en la legislación penal ${ }^{11}$ : una tipificación como delito. En estas circunstancias, pronto se entiende la frase acuñada gráficamente para estos supuestos: Eran ¿delincuentes o mártires ${ }^{12}$, ya que mientras el peso del sistema los situaba en la primera categoría, para otros debían calificarse de mártires, dado que el objetor opone "el presente de la norma con el futuro de la profecía"13.

\footnotetext{
${ }^{9}$ En la intelección del mismo contenida en la Sentencia del Tribunal Constitucional 141/2000, de 29 de mayo.

10 Vid. la excelente monografía de R. NAVARRO-VALLS y J. MARTÍNEZ-TORRÓN, Conflictos entre conciencia y Ley. Las objeciones de conciencia, lustel, Madrid, 2011, p. 29 y 31.

${ }^{11}$ Propiamente, por aquellos tiempos, el denominado Código de Justicia Militar de 17 de julio de 1945.

12 G. MUÑIZ VEGA, Los objetores de conciencia, ¿delincuentes o mártires?, Speiro, Madrid, 1974.

${ }^{13}$ R. BERTOLINO, "La libertad de conciencia: el hombre ante los ordenamientos estatales y confesionales", en Anuario de Derecho Eclesiástico del Estado, 3 (1987), p. 44.
} 
Con base en cuanto antecede, podríamos completar más esta aproximación a lo que es la objeción de conciencia, diciendo que el incumplimiento del deber jurídico realizado por razones de conciencia, es realizado por el objetor arrostrando, de mejor o peor grado, las consecuencias jurídicas derivadas del incumplimiento.

Nos detendremos ahora en un análisis más pormenorizado del referido comportamiento fáctico para, después, entrar en la valoración jurídica del mismo.

\section{a. LA OBJECIÓN DE CONCIENCIA COMO HECHO}

La persona se sitúa en una auténtica disyuntiva, pues tiene ante sí un imperativo jurídico frente a una no menos preceptiva norma de conciencia. Es obvio que sólo si se empeña en seguir los dictados de ésta, nos situaremos en el ámbito de la objeción de conciencia.

\section{1‥ EL IMPERATIVO JURÍDICO:}

El supuesto de hecho de la objeción parte del incumplimiento de un deber; deber cuya realización es jurídicamente reclamable a esa persona que lo incumple, pero ¿en virtud de qué fuente surge la exigibilidad de ese deber? Lo más normal será que venga establecido en virtud de una norma legal, pero que también puede serlo con base en un deber derivado de una relación jurídica laboral o funcionarial.

a) Si el deber es de origen legal, estaremos situados, lógicamente, en el marco del Derecho necesario o de ius cogens, no en el ámbito de lo meramente voluntario regulado por normas de Derecho dispositivo. Las Leyes imponen, por ejemplo, el deber de pagar tributos. Los partidarios de ciertas formas de objeción de conciencia fiscal entienden que, en conciencia, no deben contribuir con sus impuestos, al menos en la parte proporcional que corresponda, al sostenimiento de gastos militares, o la realización de actividades abortivas, o de experimentación con preembriones o fetos, etc.

b) El estatuto funcionarial conlleva el cumplimiento de una función pública o el desempeño de un servicio público con un conjunto de deberes que, en ocasiones, puede chocar con la conciencia de la persona. Ante la negativa de un médico a la práctica de abortos legales, cabría entonces preguntarle ¿para qué se hizo ginecólogo de la Sanidad Pública si no quería practicar abortos? Si nuestro funcionario médico lleva mucho tiempo en el cuerpo, podría llegar a sostener que cuando accedió a su estatus todo aborto era delito ${ }^{14}$, y sin embargo, tras la reforma de la Ley, en 1985, algunos supuestos devinieron legales. Si es mucho más joven no

\footnotetext{
14 Hasta la despenalización de los tres supuestos contemplados en la Ley Orgánica 9/1985, de 5 de julio, de reforma del art. 417 bis del Código Penal, a la sazón vigente.
} 
podrá aducir este tipo de razón, ¿pero sí, acaso, que su vocación es traer vidas a este mundo, no acabar con ellas? ${ }^{15}$

O el supuesto, conocido, de jueces o magistrados que se han manifestado contrarios a la autorización del denominado matrimonio homosexual, y que no se planteaban este problema cuando aprobaron la oposición, puesto que no existía más matrimonio que el heterosexual. Pero alguien que haya sacado la oposición anteayer, ¿puede tener, de todas formas, una objeción de conciencia a la celebración de ese matrimonio?

c) Si el deber jurídico deriva de una relación contractual lo que no es lógico, en principio, es firmar un contrato respecto del que no se van a poder cumplir alguna de las prestaciones exigibles en virtud del mismo. Pero puede ocurrir y ha de tomarse en consideración que las circunstancias primigenias de una persona, que harían factible el cumplimiento de esas obligaciones, resulta que pueden variar con el tiempo; especialmente cuando la persona, libremente ex art. 16 de la CE, puede cambiar de religión o ideología. Un supuesto, real, en nuestro Estado vino protagonizado por una señora que, originariamente católica, al convertirse al cristianismo adventista del séptimo día dejó de concurrir al trabajo en su empresa en el día de sábado, ya que su religión se lo prohibía, por lo que terminó siendo despedida ${ }^{16}$.

Aunque sea obvio decirlo: La existencia de un deber jurídico que haya de ser cumplido por la persona, constituye un requisito sine qua non para el posible surgimiento de la objeción de conciencia, por cuanto que sin imperativo jurídico no existe, no hay necesidad de, objeción de conciencia. Simplemente, se actuaría la libertad de la persona.

\section{EL IMPERATIVO DE CONCIENCIA:}

El incumplimiento del objetor debe responder a verdaderas, sinceras, razones de conciencia, en un ámbito, también, de necesario cumplimiento. Se trataría de normas de obligada observancia en conciencia, por lo menos, para la conciencia de esa concreta

\footnotetext{
${ }^{15}$ Algún autor ha llegado a señalar que el médico que no hace más que optar por el derecho a la vida del feto no puede ser catalogado de objetor, sino que, si acaso, habrá de serlo la mujer que quiere abortar. Cfr. J.M. GONZÁLEZ DEL VALLE, Derecho Eclesiástico Español, 2 ed., Madrid, 1991, p. 330.

16 Supuesto atendido, rechazando vulneración de los derechos a la libertad religiosa y la igualdad, por la Sentencia del Tribunal Constitucional 19/1985, de 13 de febrero.
} 
persona objetora. No estamos, por tanto, en un ámbito normativo de mera "permisibilidad" -lo que es permitido y lo que no es permitido- en conciencia. En definitiva, no estamos ante normas jurídicas, ni tampoco preceptos morales o de conciencia, que se desenvuelvan en un marco de libertad, sino que, por el contrario, son preceptos que impelen al sujeto hacia comportamientos de tipo obligatorio, pero de sentido contrario, a tenor de la norma jurídica y de la de conciencia: O sea, que ésta impide hacer lo que la norma jurídica obliga a realizar. Por ej., la negativa, basada en las creencias religiosas de unos padres, Testigos de Jehová, a las transfusiones sanguíneas, cuando éstas se consideren necesarias para salvar la vida de su hijo menor ${ }^{17}$.

Se exige, pues, sinceridad en el objetor. La dificultad en la probanza de esa sinceridad se ha venido manifestando, históricamente, a través de un sentimiento de prevención hacia aquél; con el transcurso del tiempo las negativas al cumplimiento de deberes propugnadas por determinadas creencias, fundamentalmente las sustentadas oficialmente por algunas Confesiones religiosas, han venido a "dulcificar" esa especie de probatio diabólica, rebajando las exigencias de los "Tribunales de conciencia", cuando los mismos han sido instaurados con cometidos de adverar la sinceridad del objetor ${ }^{18}$. Lo que no quiere decir que postulados sostenidos desde determinadas religiones o ideologías, y propiciadores de la actuación en conciencia, hayan de tenerse por veraces desde parámetros de universalidad. De modo que, en este punto, "hay que ponerse en la piel del objetor". No se puede entrar a valorar acerca de la legitimidad o de la veracidad, o no, de su creencia. Los Poderes Públicos es evidente que no pueden hacerlo, de conformidad con la neutralidad exigencia de la aconfesionalidad ex art. 16.3 de la Constitución- que debe de guiar su actuación. O sea, que se puede exigir al objetor que sea veraz en la creencia que dice tener, pero no que la creencia que dice tener sea verdad ${ }^{19}$.

No ha de tenerse por sincero al objetor cuando lo que guía su actuación es lo que ha venido a denominarse una objeción de conveniencia. Eso no es objeción de conciencia, es otra cosa. No es verdadera objeción de conciencia cuando, aun así denominándose y

\footnotetext{
${ }^{17}$ Cfr. la Sentencia del Tribunal Constitucional 154/2002, de 18 de julio.

18 Tal y como acontecía en Italia y en España durante la vigencia del servicio militar, donde el régimen jurídico instaurado establecía la obligación de la Administración de comprobar la veracidad de quien se declarara objetor a tal servicio; aunque, por lo que respecta a nuestro Estado, el procedimiento estaba tan desdibujado en la práctica que se satisfacía con la mera solicitud motivada, genéricamente, por el objetor. Hemos tratado en mayor profundidad esta temática en M. ALENDA SALINAS, "La objeción de conciencia al servicio militar en la Justicia constitucional emanada del Tribunal Supremo (Las "otras" estrategias "insumisas")", en VV.AA. (J. Martínez-Torrón, ed.), La libertad religiosa y de conciencia ante la Justicia Constitucional, Comares, Granada, 1998, pp. 319-331.

${ }^{19}$ Siempre que todo ello se desenvuelva dentro de criterios de razonabilidad: postulados como los sostenidos por la "Iglesia" Pastafari pueden resultar muy válidos en cuanto a la diversión, pero difícilmente pueden tener un valor axiológico equiparable a la de una genuina creencia religiosa o ideológica.
} 
siendo objeto de regulación jurídica, lo cierto es que en la aplicación práctica de la misma se desemboque en una mera opción de conciencia. Tal y como acontecía, al menos en la aplicación práctica de la Ley, durante el tiempo que estuvo vigente la P.S.S. del servicio militar, por cuanto que era mucho más liviano desempeñar aquélla que no éste. $Y$ dado que, como ya hemos adelantado, no se exigió de facto más que una declaración escrita del pretendido objetor, alegando cualquiera de los motivos genéricos (religioso, ético, moral, humanitario, filosófico) contemplados en la Ley reguladora de la objeción de conciencia al servicio militar, sin mayor especificación, para que le fuera reconocida esta condición, y con ello quedar exento del servicio militar y realizar el servicio de sustitución.

El escrúpulo de conciencia, para ser valedor de una objeción, debe responder también a criterios de razonabilidad con arreglo a los parámetros de nuestra cultura jurídica, de manera que, al amparo de aquél, no se pueden permitir comportamientos que representen una forma burda de desconocimiento de los derechos y libertades ajenos, especialmente si han de estimarse pertenecientes a una escala superior al de la indemnidad de la conciencia. Por ello, la conciencia de una persona no podría prevalecer sobre el derecho a la vida de otra (supuestos del asesino por convicción, o del mencionado Testigo de Jehová, cuando como progenitor se opone a una necesaria transfusión sanguínea para su hijo menor) y tampoco ofrecería amparo jurídico para lesionar a otro (y así, por ejemplo, la posibilidad de esterilizar a un incapaz está sujeta a autorización judicial en nuestro ordenamiento jurídico).

Así, estamos ante un mandato o prohibición establecidos por mor de un determinado ordenamiento frente a norma de conciencia (o moral) que, obligatoriamente también, impide a la persona el cumplimiento de ese deber jurídico.

En definitiva, es el ordenamiento jurídico el que no sólo obliga a hacer algo, sino que, paralelamente, impide, en el caso, a una persona actuar su libertad de creencias. Si se le permitiera obrar con arreglo a su creencia, no haría falta la objeción de conciencia ¿objeción de conciencia para qué?-. No surgiría el mecanismo de reacción que conocemos como objeción de conciencia.

El mecanismo de reacción ante la imposibilidad legal de respeto a la propia creencia -el incumplimiento del deber jurídico por razón de conciencia-, especie de cláusula de cierre del sistema en salvaguarda de la conciencia, de la creencia, que es, en definitiva, la objeción de conciencia, ¿es admisible en nuestro Ordenamiento Jurídico? ¿Halla amparo o cobertura jurídica? 


\section{b. LA OBJECIÓN DE CONCIENCIA, ¿COMO DERECHO?}

Una vez que se ha producido, por el denominado objetor, el incumplimiento de un deber, ¿qué valoración le merece al Ordenamiento Jurídico ese incumplimiento? ¿Es conducta ajustada, adecuada, a Derecho? En definitiva, estamos ante el tema de la naturaleza jurídica de la objeción de conciencia.

Con independencia de que la aspiración que guía al objetor es resultar indemne en su creencia y que, seguramente, lo que deseará es que no caiga sobre el mismo el "peso de la ley", su conducta no siempre se desenvolverá en la pretensión de cambiar la normativa jurídica que le impone el deber que deja de cumplir; pero esta pretensión, en su caso, que habitualmente se suele desarrollar en actitudes de desobediencia civil, no es tampoco descartable ${ }^{20}$.

Al principio hemos llegado a plantear si, desde el punto de vista jurídico, la objeción de conciencia tiene o no verdadera existencia; cuestión sumamente discutida en la doctrina científica, que pasamos brevemente a analizar.

Si se estima que la objeción de conciencia no tiene reconocimiento jurídico, por mucha tipicidad que pueda tener socialmente, habrá que concluir que carece de_existencia jurídica. Corolario lógico, en esta circunstancia, es su consideración como una conducta contraria a Derecho, en cuanto que el punto de partida es el incumplimiento de un deber jurídico; y, por ello, ha de recaer sobre el incumplidor todo el peso de la Ley, por muy riguroso que ello pueda parecer-dura Lex sed Lex ${ }^{21}$.

Si, por el contrario, se considera que la objeción de conciencia sí que tiene reconocimiento jurídico, habría que puntualizar que si el incumplimiento objetor halla cobijo al socaire de la libertad de creencias, no habríamos salido de la actuación de la misma; por lo que no habría lugar, en términos jurídicos, a la existencia de la objeción de conciencia. No se trataría más que de una aplicación práctica de ese derecho fundamental de libertad de creencias, puesto que la misma ampara el comportamiento personal arreglado a las que se profesan. Ahora bien, dado que este derecho no es ilimitado no puede actuarse cuando el orden público u otros bienes que merezcan el amparo constitucional impidan ese libre actuar, por sobrepasar esa esfera de agere licere en que se manifiesta el derecho que tiene toda persona con base en el art. 16 de la Carta Magna. Este es el ámbito propio del posible surgimiento de la objeción de conciencia: con base y en defensa de las propias creencias

\footnotetext{
${ }^{20}$ Acerca de las dificultades de delimitación conceptual entre objeción de conciencia y desobediencia civil, vid., entre otros, R. NAVARRO-VALLS y J. MARTÍNEZ-TORRÓN, Conflictos entre conciencia y Ley..., cit., p. 29 s.

${ }^{21}$ En su fase extrema, si de lo que se trata es del incumplimiento de preceptos penales, será, según los casos, una antijuridicidad de tipo penal.
} 
que, sin embargo, no pueden defenderse desde una actuación ordinaria del derecho de libertad de creencias, al hallarse el mismo debidamente delimitado en su configuración legal o legítimamente restringido en base al establecimiento por el legislador de un deber jurídico constitutivo de orden público ${ }^{22}$.

Otro tanto habría que afirmar si el incumplimiento del deber exigible al sujeto puede ampararse en una configuración jurídica que, aun respondiendo al nomen iuris de la objeción de conciencia, no sea representativa más que de una opción de conciencia. De manera que se puede producir la paradoja de que la objeción de conciencia no será tal sin reconocimiento jurídico explícito; y que, si alcanza ese status, deje de serlo para transformarse en una mera opción de conciencia.

En consecuencia, si verdaderamente se quiere que la objeción de conciencia tenga autonomía jurídica suficiente como derecho, a nuestro juicio sólo se puede salvar: 1o) manteniendo la obligatoriedad del deber jurídico, como regla general, caracterizando la exención del mismo a través del mecanismo de la objeción como excepcional: por tanto, la configuración legal en la materia debe de ser la de regla general-excepción y no la de dos meras alternativas iguales en la concesión de una opción; y 2o) la excepción (objeción de conciencia) sólo se podrá reconocer, previa justificación, para cada caso concreto; como corresponde a un verdadero fenómeno individual como es la conciencia.

Un sector doctrinal viene sosteniendo que la objeción de conciencia es un derecho fundamental, que está reconocido en el art. 16 de la CE, como formando parte del mismo. En sustento de esta afirmación se sigue buscando apoyo en algunas afirmaciones del Tribunal Constitucional, como las proclamadas en las ya citadas Sentencias 15/1982 y $53 / 1985$, en las que se viene a señalar el entronque, parece que incontestable desde luego a tenor de estas resoluciones, de la objeción de conciencia con el art. 16 de la CE y el derecho que este proclama a la libertad de creencias. Sin embargo, este art. 16 de la Carta Magna no habla, expressis verbis al menos, de la objeción de conciencia. ¿Cabe, entonces, un derecho a la objeción de conciencia con carácter general basada en este precepto? Como ya hemos adelantado, al principio de este trabajo, el Tribunal Constitucional, con posterioridad a las resoluciones acabadas de citar, ha dicho, con carácter expreso y categórico, que no cabe un derecho general a la objeción de conciencia, entendido como un derecho que autorice para eximir del cumplimiento de deberes constitucionales o

\footnotetext{
${ }^{22}$ Conforme autorizan el propio art. 16.1 de la CE y el art. 3.1 de la Ley Orgánica de Libertad Religiosa de 5 de julio de 1980.
} 
legales. Un derecho de tal naturaleza no está reconocido en nuestro Derecho ni en Derecho alguno, pues sería acabar con la idea misma de la existencia del Estado.

Por tanto, no cabe más objeción de conciencia que la "juridificada". Esta doctrina del Tribunal Constitucional ha sido ampliamente seguida por la Jurisprudencia del Tribunal Supremo, tanto en cuestiones que se han desenvuelto en el marco de la jurisdicción contencioso-administrativa (objeción de conciencia al estudio de la asignatura 'Educación para la ciudadanía' ${ }^{23}$ y objeción de conciencia en relación con la tramitación registral del expediente prematrimonial entre personas del mismo sexo ${ }^{24}$ ), como en el ámbito de la jurisdicción penal (objeción de conciencia al cumplimiento de la P.S.S. del servicio militar ${ }^{25}$ y objeción de conciencia a formar parte de una mesa electoral ${ }^{26}$ ).

En la línea evolutiva mantenida por el Tribunal Constitucional, suficientemente referida, parece que el corolario lógico hubiera sido seguir sosteniendo, en su reciente Sentencia de 25 de junio de 2015, que no cabe más objeción de conciencia que la "juridificada", de manera que al no estarlo la objeción farmacéutica el resultado debería haber sido el de la desestimación del recurso de amparo, tal y como se propugna en uno de los votos particulares contenidos en la propia Sentencia. Sin embargo, el alto Tribunal no viene a desconocer esta doctrina, sino que sigue confirmándola al menos en parte, si bien sin dejar de hacer valer cuanto también había sostenido en la Sentencia 53/1985 respecto de la objeción al aborto. El máximo intérprete de la Carta Magna distingue en esta materia y en relación a la objeción manifestada por el farmacéutico recurrente dos distintos aspectos:

1. La objeción de conciencia al aborto, manifestada en la negativa a la tenencia, para expendición, de la denominada píldora del día después.

El alto Tribunal estima que a esta negativa, sancionada por la Administración andaluza por incumplimiento de la normativa aprobada por la misma al respecto, le es aplicable la doctrina sostenida por el propio Tribunal en la citada sentencia de 1985, sobre objeción de conciencia al aborto ${ }^{27}$. Para ello el Tribunal no duda en realizar una interpretación amplia y flexible sobre la posibilidad abortiva de la mencionada píldora, acogiendo las convicciones del farmacéutico, con independencia de que ese efecto abortifaciente hubiera de

\footnotetext{
${ }^{23}$ Varias Sentencias del Tribunal Supremo de 11 de mayo de 2009 y Sentencia del Tribunal Supremo de 5 de junio de 2009.

${ }^{24}$ Sentencia del Tribunal Supremo de 11 de mayo de 2009.

${ }^{25}$ Sentencia del Tribunal Supremo de 9 de diciembre de 1997.

${ }^{26}$ Acerca de esta problemática: Sentencias del Tribunal Supremo de 30 de enero de 1979, 23 de diciembre de 1992, 30 de diciembre de 1992, 30 de marzo de 1993, 8 de junio de 1994, 14 de diciembre de 1994,27 de marzo de 1995, 28 de octubre de 1998 y 28 de diciembre de 2007.

${ }^{27}$ Cfr. el FJ 4 de la Sentencia.
} 
producirse verdaderamente, o no, en la práctica, y con independencia de las voces contrarias a ese efecto abortivo (desde la OMS hasta la propia doctrina del Tribunal Constitucional sobre la protección debida al nasciturus y a los "embriones" y "preembriones" $)^{28}$ a atribuir a la píldora.

Manifestado cuanto antecede por el alto Tribunal, complementando o por si no fuera suficiente esta caracterización "legal" de la objeción de conciencia al aborto hacia el farmacéutico, acaso buscando el cobijo de la "juridificación" exigida para poder hacer valer otros supuestos de objeción de conciencia, se alude a la objeción de conciencia farmacéutica que, a falta de un reconocimiento normativo más explícito en la legislación farmacéutica andaluza (a diferencia del de otras Comunidades Autónomas, como hemos dicho) trata de hallarse, en la Orden andaluza, de 8 de mayo de 2006, que valida los Estatutos del Colegio de Farmacéuticos de Sevilla, que sí contempla la posibilidad de esa objeción farmacéutica ${ }^{29}$. La cuestión surge de inmediato: ¿Si la objeción de conciencia en análisis tiene amparo en el art. 16 de la CE, qué necesidad hay de acudir a esa "juridificación de la misma" en la referida Orden de la Consejería de Justicia y Administración Pública de la Junta de Andalucía?

Parece que una cosa es la posibilidad de fundamentación de la objeción de conciencia y su surgimiento con base en el art. 16.1 de la CE, que constituye su "nodriza ética" ${ }^{30}$, en cuanto que actuación fáctica del sujeto que cuenta como valedor con un "derecho en germen" en nuestro ordenamiento jurídico (STC 53/1985 y la reciente de 25 de junio de 2015). Y otra es que esa objeción de conciencia pueda convertirse, per se, en un "derecho firme" a la exención del cumplimiento del deber jurídicamente establecido (conforme a la numerosa jurisprudencia a la que hemos aludido). Tendrá que ser el legislador, explícita o implícitamente, el que establezca esta posibilidad, que habrán de determinar, en última instancia, los operadores del Derecho.

2. Sea tal vez por todo ello que ni el art. 16 de la CE ni la normativa andaluza pro objeción de conciencia farmacéutica tienen virtualidad alguna respecto de la negativa a la tenencia, de cara a la dispensación, de preservativos; objeto también del recurso de amparo sostenido por el boticario. En este último caso el Tribunal Constitucional sin ambages ha sostenido, escuetísimamente, que "[v]istas las razones que nos han conducido a considerar que la falta de existencias, en el

\footnotetext{
${ }^{28}$ Cfr. las Sentencias del Tribunal Constitucional 212/1996, FJ 13 y 116/1999, de 17 de junio, FJ 9.

${ }^{29} \mathrm{Cfr}$. el FJ 5 de la Sentencia.

30 Cfr. G. PECES-BARBA MARTínEZ, "Desobediencia civil y objeción de conciencia”, en Anuario de Derechos Humanos, 5 (1988-1989), p. 174.
} 
establecimiento citado, del principio activo levonorgestrel 0’75 mg queda amparada por el art. 16.1 CE, es patente que el incumplimiento de la obligación relativa a las existencias de preservativos queda extramuros de la protección que brinda el precepto constitucional indicado. La renuencia del demandante a disponer de profilácticos en su oficina de farmacia no queda amparada por la dimensión constitucional de la objeción de conciencia que dimana de la libertad de creencias reconocida en el art. 16.1 CE. Ningún conflicto de conciencia con relevancia constitucional puede darse en este supuesto" ${ }^{31}$.

Esta fundamentación tan nimia no alcanza a explicar por qué, en el caso del supuesto efecto abortivo, la objeción de conciencia farmacéutica ampara la conducta del boticario renuente al almacenamiento de la píldora del día después; y, sin embargo, en el supuesto de esa misma negativa hacia los profilácticos por entender que la venta de los mismos resulta inmoral, según las convicciones del mismo, la objeción no tiene virtualidad jurídica alguna ${ }^{32}$.

En nuestra opinión, la objeción de conciencia no es un derecho fundamental, o al menos no podrá considerarse que forma parte de su contenido esencial: 1) Porque, si fuera derecho fundamental, no habría tal objeción de conciencia, sino ejercicio libre, puro y duro, de ese derecho fundamental. 2) Porque si formara parte del contenido esencial del derecho fundamental, su ejercicio no podría someterse a fiscalización, a fin de poder dejarlo sin efecto práctico consecuente, pues sería tanto como desdibujar ese contenido esencial del derecho, lo que proscribe nuestro ordenamiento ${ }^{33}$.

¿Entonces, qué es la objeción de conciencia? No puede tenerse, en su caso, más que como una facultad jurídica, que necesita ser habilitada por el legislador para su existencia, en el seno de la delimitación del cumplimiento de un concreto deber jurídico, instituyendo un mecanismo en virtud del cual se permite el incumplimiento de una norma jurídica con base en las creencias -que habrán de acreditarse- del sujeto objetor; 0 , al menos, que la negativa del mismo sea atendible a efectos de atenuación de las consecuencias jurídicas derivadas de su incumplimiento; cualquiera de estas dos posibilidades, como consecuencia de un ejercicio práctico de ponderación de los derechos en conflicto o intereses en juego.

\footnotetext{
${ }^{31}$ Vid. FJ. 6 de la Sentencia en análisis.

32 El propio ponente de la sentencia critica este "doble rasero" en su voto particular que, aunque denomina concurrente, revela que no participa con la totalidad de la fundamentación y resultado alcanzado en la misma.

${ }^{33}$ Cfr. Sentencias del Tribunal Constitucional 37/1987, de 26 de marzo, FJ 2 y 112/2006, de 5 de abril, FJ 10.
} 


\section{ALGUNAS MANIFESTACIONES DE OBJECIÓN DE CONCIENCIA}

En definitiva y si la objeción de conciencia, para ser tal, ha de estar "juridificada", ¿hay presencia de la misma en nuestro Ordenamiento Jurídico? La respuesta ha de ser afirmativa, en algunas de sus concretas manifestaciones, siendo paradigmática, en este sentido, la objeción al servicio militar en contraste con otras manifestaciones de la objeción, cuya admisión viene siendo bastante excepcional y en términos restrictivos. Veamos, aunque sea brevemente, estos supuestos.

\section{a. OBJECIÓN DE CONCIENCIA AL SERVICIO MILITAR}

Es la única que viene reconocida al más alto nivel legal, ya que el art. 30.2 de la Carta Magna proclama que "La ley fijará las obligaciones militares de los españoles y regulará, con las debidas garantías, la objeción de conciencia, así como las demás causas de exención del servicio militar obligatorio, pudiendo imponer, en su caso, una prestación social sustitutoria".

Esta regulación se llevó a cabo, originariamente, por la Ley Orgánica 8/1984, de 26 de diciembre (que regulaba el régimen penal y de recursos) y la Ley 48/1984, de 26 de diciembre, derogada y sustituida por la Ley 22/1998, de 6 de julio. Dado que el servicio militar quedó en suspenso a partir del 31 de diciembre de $2001^{34}$, en el actual ordenamiento normativo español la objeción de conciencia al mismo constituye un instituto jurídico latente, en cuanto que aunque se trata de un derecho vigente y plenamente reconocido, sin embargo la posibilidad de su ejercicio $-y$, por tanto, de su manifestación- carece de eficacia, por lo menos en cuanto al servicio militar obligatorio se refiere. Dos excepciones cabría señalar: una, ya pretérita y que fue de carácter transitorio en el ámbito del propio servicio militar obligatorio, por lo que respecta a los reservistas del mismo que, en esta situación, hubieran querido ejercitar su derecho de objeción de conciencia; otra, en el seno del ejército profesional por quien ya forma parte del mismo, supuesto que ha sido calificado por algunos autores como genuino instituto objetor. ${ }^{35}$

\footnotetext{
${ }^{34}$ En virtud del Real Decreto 247/2001, de 9 de marzo y la Disposición Adicional 13a de la Ley 17/1999, de 18 de mayo, de Régimen del Personal de las Fuerzas Armadas. Por su parte, el Real Decreto 342/2001, de 4 de abril, dejó en suspenso la P.S.S. del servicio militar.

${ }^{35}$ Con mayor profundidad, hemos tratado de este tipo de objeción en M. ALENDA SALINAS, "Objeción de conciencia al servicio militar", en Materiales para el estudio del Derecho (Manual online en el Portal Jurídico lustel.com)
} 
En cualquier caso, en el proceso legislativo tendente a instaurar la absoluta profesionalización del Ejército, que supusiera la desaparición del servicio militar obligatorio, no se dejó de ser consciente de que pudieran no conseguirse plenamente los objetivos esperados. Es por ello que tanto la Ley 17/1999, de 18 de mayo, de Régimen del Personal de las FAS [Fuerzas Armadas], primero y la actualmente vigente Ley 39/2007, de 19 de noviembre, de la Carrera Militar, contienen también la previsión de que las necesidades de la defensa nacional no puedan ser atendidas únicamente por los efectivos de militares profesionales. Para este supuesto se regula la posibilidad de aportación de recursos humanos a las FAS, estableciéndose las condiciones en que el Gobierno pueda adoptar las medidas necesarias para la incorporación de reservistas a las mismas. La propia Ley contempla la hipótesis de que entre esos reservistas, además de los que califica de "voluntarios" y de "especial disponibilidad", pueda también tener que hacerse uso de reservistas "obligatorios".

Para este último supuesto, el Gobierno habrá de solicitar del Congreso de los Diputados autorización para la declaración general de reservistas obligatorios, que podrá afectar a todos los españoles que en ese año cumplan desde 19 a 25 años de edad. Resulta curioso constatar cómo el procedimiento para la selección de estos reservistas se ha establecido en forma semejante al que se seguía para el reclutamiento del servicio militar y, por otro lado, se prevé que la incorporación de los mismos pueda ser tanto a las FAS, como a otras organizaciones con fines de interés general para satisfacer las necesidades de la defensa nacional.

Siguiendo con las hipótesis concatenadas, se ha previsto también que, de acontecer tales circunstancias, pueda surgir la objeción de conciencia. Así el art. 138 de la Ley 39/2007 señala al respecto que "Ios reservistas obligatorios podrán efectuar declaración de objeción de conciencia a prestar servicio en las FAS y en otras organizaciones con fines de interés general en las que se requiera el empleo de armas. Dicha declaración, efectuada por el interesado, no requerirá ningún otro trámite de reconocimiento".

Esta Ley opta decididamente por aceptar la "autodeclaración" como objetor del propio interesado, teniendo la misma plenos efectos sin necesidad de pláceme administrativo alguno (tal y como sí que exigía la anterior regulación legal en la materia), limitándose a dejar constancia oficial a tales menesteres. La consecuencia de ello es que "los que se hayan declarado objetores de conciencia sólo podrán ser asignados a organizaciones con fines de interés general en las que no se requiera el empleo de armas" (art. 138).

\section{b. OBJECIÓN DE CONCIENCIA SANITARIA}

La posibilidad de hacer valer por el profesional sanitario la OBJECIÓN DE CONCIENCIA AL ABORTO, fue reconocida, en un obiter dictum, en la ya citada Sentencia del Tribunal 
Constitucional 53/1985, de 11 de abril; con una fundamentación que, sin embargo, posteriormente y a tenor de la evolución de la doctrina de tan alto Tribunal, parece que hubiera sido difícilmente sostenible. No obstante, como hemos visto, el grueso de aquellas afirmaciones, aunque con algún complemento se ha mantenido en la reciente Sentencia de 25 de junio de 2015

En cualquier caso, la posibilidad objetora del médico y asistentes a la práctica del aborto se ha mantenido inalterable, en la práctica, desde aquella Sentencia de 1985. Y ello hasta el punto de que cuando se propuso legislar la reforma de los supuestos en que era legalmente admisible el aborto, no se incluyó ninguna previsión legislativa en este sentido. Finalmente, sin embargo, la Ley Orgánica 2/2010, de 3 de mayo, de Salud Sexual Reproductiva y de la Interrupción Voluntaria del Embarazo, sí contiene en su art. 19.2 el reconocimiento de este derecho, al establecer: "Ios profesionales sanitarios directamente implicados en la interrupción voluntaria del embarazo tendrán el derecho de ejercer la objeción de conciencia, sin que el acceso y la calidad asistencial de la prestación puedan resultar menoscabadas por el ejercicio de la objeción de conciencia. El rechazo o la negativa a realizar la intervención de interrupción del embarazo por razones de conciencia es una decisión siempre individual del personal sanitario directamente implicado en la realización de la interrupción voluntaria del embarazo, que debe manifestarse anticipadamente y por escrito. En todo caso los profesionales sanitarios dispensarán tratamiento y atención médica adecuados a las mujeres que lo precisen antes y después de haberse sometido a una intervención de interrupción del embarazo."

En relación con la última parte de este precepto, referente a la forma de poder hacer valer la objeción, el Tribunal Constitucional, en Sentencia 151/2014, de 25 de septiembre, ha declarado que es perfectamente ajustado a la Constitución, "la creación de un registro autonómico de profesionales en relación con la interrupción voluntaria del embarazo con la finalidad de que la Administración autonómica conozca, a efectos organizativos y para una adecuada gestión de dicha prestación sanitaria, quienes en ejercicio de su derecho a la objeción de conciencia rechazan realizar tal práctica, [pues] su existencia no implica, per se, un límite al ejercicio del derecho a la objeción de conciencia recogido en el art. 19.2 de la L.O. 2/2010, ni un sacrificio desproporcionado e injustificado de los derechos a la libertad ideológica e intimidad", dado que "este derecho ha de hacerse compatible con lo dispuesto en el art. 18 de la misma Ley, en el que se fija que "los servicios públicos de salud, en el ámbito de sus respectivas competencias, aplicarán las medidas precisas para garantizar el derecho a la prestación sanitaria de la interrupción voluntaria del embarazo en los supuestos y con los requisitos establecidos en esta Ley. Esta prestación estará incluida en la cartera de servicios comunes del Sistema Nacional de Salud", así como con lo previsto en el 
art. 17 de la citada norma, que fija, entre otros extremos, que todas las mujeres que manifiesten su intención de someterse a una interrupción voluntaria del embarazo "recibirán información sobre los distintos métodos de interrupción del embarazo, las condiciones para la interrupción previstas en esta Ley, los centros públicos y acreditados a los que se pueda dirigir y los trámites para acceder a la prestación, así como las condiciones para su cobertura por el servicio público de salud correspondiente".

Aunque este derecho reconocido a los facultativos y personal paramédico se ha sostenido que podría hacerse extensivo a otros casos en los que se requiere la intervención de la lex artis del profesional sanitario como es el relativo, por ej., a la práctica legal de esterilización de incapaces, y algunas regulaciones de Comunidad Autónoma no dudan en aludir a la objeción de conciencia en materia de cumplimiento de mandatos relativos a la atención sanitaria, derivados de documentos de voluntades anticipadas ${ }^{36}$, lo cierto es que la posibilidad de extensión a otros supuestos resulta de muy complicada aplicación, si hemos de atenernos a algunos casos resueltos judicialmente, en que se ha denegado esa posibilidad de cobijo de una objeción de conciencia, al amparo del paraguas de la reconocida al profesional médico y asistentes sanitarios en el caso del aborto, a funcionarios del cuerpo de Asistentes Técnico-Sanitarios de instituciones penitenciarias que se han negado a suministrar metadona a reclusos como sustitutivo de las drogas de que eran dependientes ${ }^{37}$, o a participar en un programa de intercambio de jeringuillas ${ }^{38}$.

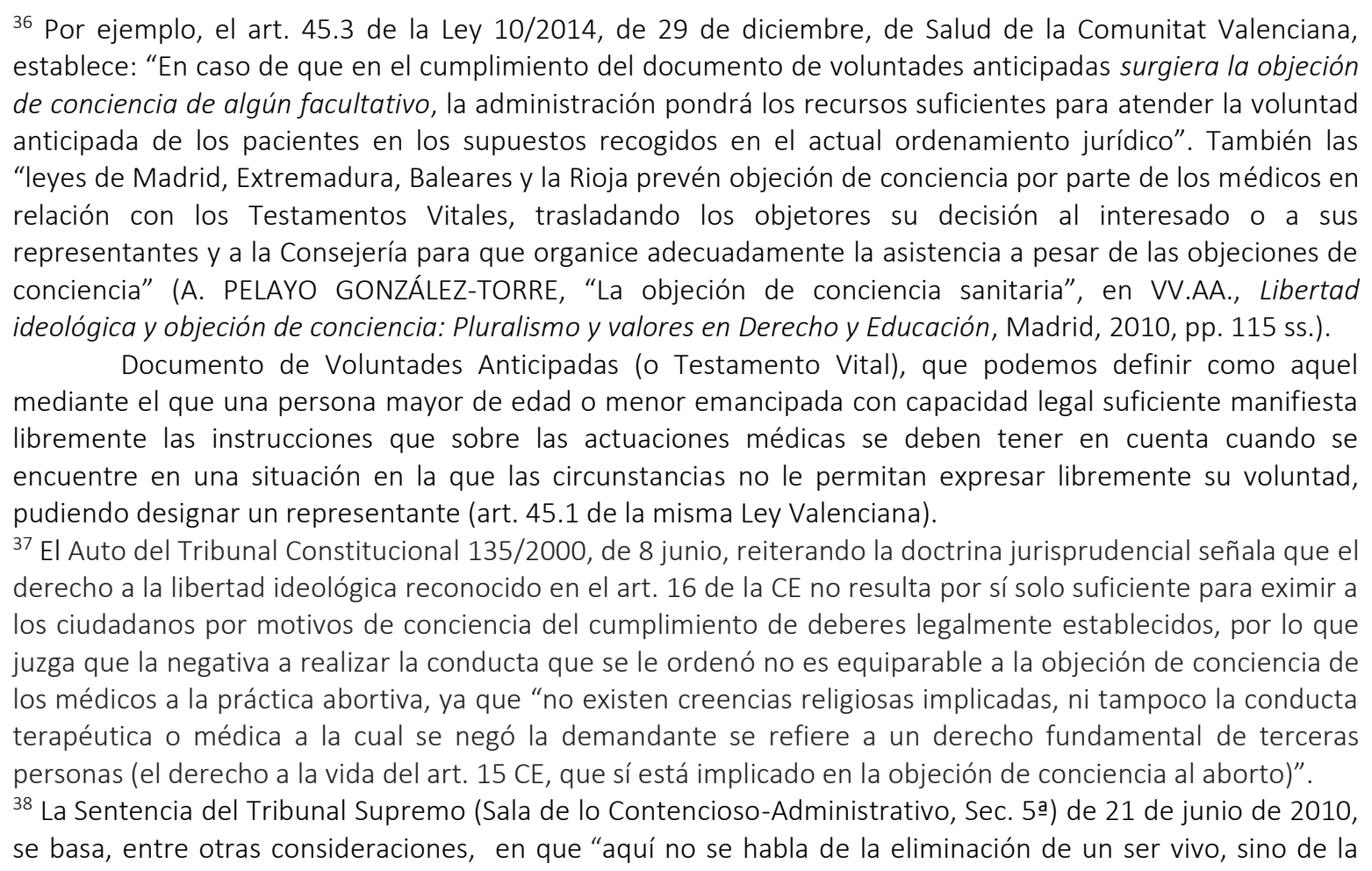


En cualquier caso, entendemos que estaría justificada la negativa del personal sanitario a participar en supuestos que serían propiamente de eutanasia, desde luego porque hoy por hoy es un delito ${ }^{39}$, así como en los supuestos legales de esterilización de incapaces ${ }^{40}$ y otros casos desenvueltos en el campo de la bioética (como por ej., supuestos de reproducción asistida, incluida la gestación de sustitución, especialmente si todo ello conlleva la práctica abortiva o de eliminación de embriones sobrantes) ${ }^{41}$.

Sin embargo, no consideramos que la transfusión sanguínea a los Testigos de Jehová ni la intervención médica en casos de huelga de hambre sean casos subsumibles bajo el supuesto de la objeción de conciencia del profesional sanitario. Sin duda que a estos últimos se les puede suscitar, en tales supuestos, un grave dilema ético, al considerar que la vida está por encima de cualquier otra consideración, pero el problema habrá de solventarse desde otros postulados diversos al de la objeción de conciencia; y entre ellos:

1. La necesidad de obtener el consentimiento informado del paciente que requiera de cualquier intervención quirúrgica o tratamiento sanitario (art. 8 de la Ley 41/2002, de 14 de noviembre, básica reguladora de la autonomía del paciente y de derechos y obligaciones en materia de información y documentación clínica).

2. Los facultativos podrán llevar a cabo las intervenciones clínicas indispensables en favor de la salud del paciente, sin necesidad de contar con su consentimiento, en los siguientes casos: a) Cuando existe riesgo para la salud pública a causa de razones sanitarias establecidas por la Ley. En todo caso, una vez adoptadas las medidas pertinentes, de conformidad con lo establecido en la Ley Orgánica 3/1986, se comunicarán a la autoridad judicial en el plazo máximo de 24 horas siempre que dispongan el internamiento obligatorio de personas. b) Cuando existe riesgo inmediato grave para la integridad física o psíquica del enfermo y no es posible

atención sanitaria a un problema concreto, que se sabe existente y que no se confía en suprimir de raíz, mediante el suministro de material que evite determinados perjuicios para la salud de los internos del Centro Penitenciario".

${ }^{39}$ El art. 143.4 del Código Penal, aunque con una pena atenuada, sanciona a quien "causare o cooperare activamente con actos necesarios y directos a la muerte de otro, por la petición expresa, seria e inequívoca de éste, en el caso de que la víctima sufriera una enfermedad grave que conduciría necesariamente a su muerte, o que produjera graves padecimientos permanentes y difíciles de soportar".

40 El art. 156, párrafo 2, del Código Penal establece que no será punible la esterilización de persona incapacitada que adolezca de grave deficiencia psíquica cuando aquélla, tomándose como criterio rector el del mayor interés del incapaz, haya sido autorizada judicialmente.

${ }^{41}$ Atiende los diversos supuestos "problemáticos", B. GONZÁLEZ MORENO, "El personal sanitario ante las nuevas técnicas de reproducción humana asistida y de la investigación biomédica", en VV.AA. (M. Roca, coord.), Opciones de conciencia. Propuestas para una Ley, Tirant lo Blanch, Valencia, 2008, pp. 271 ss. 
conseguir su autorización, consultando, cuando las circunstancias lo permitan, a sus familiares o a las personas vinculadas de hecho a él (art. 9.2 de la misma Ley 41/2002, de 14 de noviembre).

3. En el caso de necesidad vital de transfusión sanguínea, ante la negativa a la misma por parte de testigos de Jehová, habrá que distinguir si la persona es mayor de edad y está en el ejercicio de sus facultades mentales, en que habrá de respetarse su voluntad al respecto; y si es menor de edad sin condiciones de madurez, en cuyo caso no podrá prevalecer la decisión de sus padres al respecto, pudiendo acudirse por el profesional médico a la autoridad judicial en demanda de autorización, sin perjuicio de que pueda prescindir de la misma atendiendo a razones de estado de necesidad y cumplimiento de un deber. Si el menor es suficientemente maduro (1617 años), se respetará su decisión si es favorable a la transfusión, aunque sus padres se opongan; en otro caso y si es apoyado por sus padres al respecto, habrá de acudirse a la autorización judicial ${ }^{42}$.

4. En el caso de las huelgas de hambre de presos, el Tribunal Constitucional consideró perfectamente ajustado a Derecho la alimentación forzosa de los mismos, dada la posición de garante de la vida que el Estado tiene de los internos en estas situaciones de especial sujeción ${ }^{43}$.

\section{c. OBJECIÓN DE CONCIENCIA FARMACÉUTICA}

Supuesto discutido en relación con la posibilidad de producción de un efecto abortifaciente es el referido a la denominada píldora del día después, o píldora postcoital, habiéndose

\footnotetext{
42 Vid. la Circular 1/2012, de 3 de octubre, de la Fiscalía General del Estado, sobre el tratamiento sustantivo y procesal de los conflictos ante transfusiones de sangre y otras intervenciones médicas sobre menores de edad en caso de riesgo grave.

43 STC 120/1990, de 27 de junio: "Tiene, por consiguiente, el derecho a la vida un contenido de protección positiva que impide configurarlo como un derecho de libertad que incluya el derecho a la propia muerte. Ello no impide, sin embargo, reconocer que, siendo la vida un bien de la persona que se integra en el círculo de su libertad, pueda aquélla fácticamente disponer sobre su propia muerte, pero esa disposición constituye una manifestación del agere licere, en cuanto que la privación de la vida propia o la aceptación de la propia muerte es un acto que la ley no prohíbe y no, en ningún modo, un derecho subjetivo que implique la posibilidad de movilizar el apoyo del poder público para vencer la resistencia que se oponga a la voluntad de morir, ni, mucho menos, un derecho subjetivo de carácter fundamental en el que esa posibilidad se extienda incluso frente a la resistencia del legislador, que no puede reducir el contenido esencial del derecho. En virtud de ello, no es posible admitir que la Constitución garantice en su art. 15 el derecho a la propia muerte y, por consiguiente, carece de apoyo constitucional la pretensión de que la asistencia médica coactiva es contraria a ese derecho constitucionalmente inexistente".
} 
producido alguna resistencia a su expendición por parte de farmacéuticos, fundamentalmente en Andalucía, dado que en esta Comunidad Autónoma se estableció por una Orden del año 2001 la obligación de tenencia de tal producto por parte de todas las Oficinas de Farmacia. Esa preceptiva legal fue impugnada ante los Tribunales, habiendo recaído sentencias al respecto, tanto del Tribunal Superior de Justicia de Andalucía (de 8 de enero de 2007), como por parte del Tribunal Supremo (23 de abril de 2005), en virtud de las cuales un sector doctrinal estima que tales Tribunales han otorgado carta de reconocimiento a la objeción de conciencia de los farmacéuticos ${ }^{44}$; postura que no se puede compartir, por las razones en virtud de las cuales ya manifestábamos nuestras dudas al respecto ${ }^{45}$, que se vieron confirmadas por el propio Tribunal Supremo con ocasión de su rechazo a la objeción de conciencia al estudio de la asignatura 'Educación para la Ciudadanía'. ${ }^{46}$ En uno y otro caso, como hemos venido propugnando, habría sido mejor, en términos de pragmatismo jurídico, haber suscitado en el foro estas "resistencias" no como supuestos de objeción de conciencia (dada su falta explícita de reconocimiento legal), sino como de vulneración del derecho de libertad de creencias y de comportamiento con arreglo a las mismas ${ }^{47}$.

44 Así, por ej., A. GONZÁLEZ-VARAS, "Las objeciones de conciencia de los profesionales de la salud", en Opciones de conciencia, cit., p. 321 y R. NAVARRO-VALLS y J. MARTÍNEZ-TORRÓN, Conflictos entre conciencia y Ley... cit., p. 171.

45 M. ALENDA SALINAS, "La píldora del día después: su conflictividad jurídica como manifestación de la objeción de conciencia farmacéutica», en Revista General de Derecho Canónico y Eclesiástico del Estado, 16 (2008).

46 “La Sala 3a del Tribunal Supremo, en su sentencia de fecha 11 de mayo de 2009, como el recurrente hacía hincapié en tales declaraciones confiriéndoles el valor de precedente, y sabedora, a su vez, de que así lo ha entendido alguna doctrina, se apresura a manifestar que «no cuesta trabajo advertir que la mención a la objeción de conciencia se efectúa en el contexto de una argumentación a mayor abundamiento y ajena a la ratio decidendi, se limita a reiterar lo que sobre la misma dijo el TC en su sentencia 53/1985 y a formular una afirmación abstracta en términos negativos que se limita a no excluir el derecho que a la misma podría corresponder a los profesionales sanitarios afectados, reconociendo, sin embargo, que no es aplicable al supuesto enjuiciado»." Vid. J.E. PECES MORATE, "La objeción de conciencia en la jurisprudencia española", en www.funciva.org/uploads/ficheros_documentos/1248356064_peces_morate.pdf (2009).

47 Y así, con motivo de los recursos contra la asignatura 'Educación para la Ciudadanía', ante el Tribunal Supremo se vino a aducir por los interesados: Del mismo modo, reprochan a la Sentencia recurrida un defecto en la identificación del objeto procesal. Sostienen que lo que defendían efectivamente no era tanto la existencia o no de un derecho a la objeción de conciencia, sino si se ha vulnerado el derecho fundamental que les asiste como padres (art. 27.3 CE) a elegir la educación moral de sus hijos conforme a sus convicciones; previsión constitucional que estiman conculcada con base en el juego combinado de ese derecho fundamental y del de libertad ideológica, religiosa y de conciencia. La invocación de la objeción, así, afirman, resultaba sólo un expediente técnico o medio instrumental, de manera que, centrándose en ésta y no en aquellos derechos fundamentales, el Tribunal Supremo no dirimió tampoco desde ese prisma la controversia formulada, alterando el objeto de debate. 
El supuesto de objeción de conciencia farmacéutica cuenta, con todo, con algún reconocimiento en legislaciones autonómicas que, a nuestro juicio, sin embargo, no logran superar el mandato contenido en la Ley 29/2006, de 26 de julio, de garantías y uso racional de los medicamentos y productos sanitarios, que establece que las oficinas de farmacia vienen obligadas a dispensar los medicamentos que se les demanden tanto por los particulares como por el Sistema Nacional de Salud en las condiciones reglamentarias establecidas (art. 84.3), considerando infracción grave "negarse a dispensar medicamentos o productos sanitarios sin causa justificada" (art. 101.b).15a), así como "cualquier acto u omisión encaminado a coartar la libertad del usuario en la elección de la oficina de farmacia" (art. 101.b).26á) y como infracción muy grave, además de "cometer tres infracciones calificadas como graves en el plazo de dos años", la de "no disponer de las existencias de medicamentos adecuadas para la normal prestación de sus actividades o servicios" (art. 101.c).12a y 21a $)^{48}$.

Esta Ley no contempla, pues, la objeción de conciencia como tal, pero sí establece que la obligación de dispensación lo es "salvo causa justificada". ¿Puede constituirla el ejercicio de la libertad de creencias? Si hemos de atender al caso que en estos términos fue suscitado por farmacéuticos franceses ante el Tribunal Europeo de Estrasburgo, no parece que la libertad religiosa pueda ser considerada a estos efectos. Según la Decisión del Tribunal, de fecha 2 de octubre de 2001, en una concepción que nos parece absolutamente muy estrecha de las cosas, el farmacéutico no puede hacer prevalecer e imponer a otro sus convicciones religiosas para justificar el rehúse de la venta del fármaco; de manera que, lejos de llevar a cabo un efectivo y equitativo balance para resolver el conflicto de los derechos en litigio, el Tribunal opta por el sacrificio total y absoluto de la libertad religiosa frente al derecho a la dispensación medicamentosa. Puede que tal decisión estuviese condicionada por el Derecho interno francés, al establecer un monopolio farmacéutico en la expendición de medicamentos y la aplicación, dispuesta en forma expresa legal, de la legislación de consumidores; pero no consideramos que haya de mantenerse a ultranza esta postura, cuando ello supone una privación tajante de la libertad de creencias, siendo que hay posibilidades de satisfacer todos los intereses en conflicto, que es lo que reclamaría un buen balance de la situación ${ }^{49}$. ¿Será, entonces, que hay que acudir al recurso de la objeción de conciencia aunque haya de suscitarse ante los Tribunales,

\footnotetext{
${ }^{48}$ La sanción para las infracciones graves puede ir, según graduación de la conducta, desde los 30.001 hasta los 90.000 euros.

${ }^{49}$ Cfr. A. GONZÁLEZ-VARAS, “La objeción de conciencia del farmacéutico...", cit., p. 12. Sobre el particular: N. GIMELLI, "L'obezione di coscienza dei farmacisti: cosa ne pensa la Corte Europea dei Diritti dell'uomo? II caso Pichon e altri c. Francia. II dibatitto dottrinale italiano sulla c.d. "pillola del giorno dopo" ", en // Diritto Ecclesiastico, 2004, pp. 740 ss. El texto de la resolución judicial puede consultarse en la web del Osservatorio delle libertà ed istituzioni religiose (www.olir.it).
} 
dejándolo absolutamente claro ante los mismos, con carácter subsidiario al del derecho de libertad de creencias?

La ausencia de referencia en la Ley estatal sobre la materia a la objeción de conciencia contrasta con la de algunas Leyes autonómicas, que sí que aluden a la posibilidad de empleo de este instituto por parte del farmacéutico, aunque tales regulaciones tampoco llegan a especificar en qué consiste en concreto la misma. Así sucede con las Leyes cántabra, riojana, gallega y castellano-manchega en materia farmacéutica ${ }^{50}$. En cambio, no se contempla nada al respecto, aparte de en Andalucía, en las Leyes de Farmacia de Navarra, Valencia, Asturias ni Extremadura.

Finalmente, sin embargo, ya hemos visto cómo el Tribunal Constitucional ha amparado la objeción de conciencia farmacéutica, pero sólo por lo que se refiere a la negativa al almacenamiento de la píldora del día después, haciéndolo, tal y como habíamos propugnado $^{51}$, con un entendimiento extensivo de la objeción de conciencia al aborto; no así respecto del rehúse a la disposición de preservativos, rechazado por el alto Tribunal al conocer del recurso de amparo por la sanción de $3.300 €$ impuesta a un farmacéutico andaluz por no disponer en su botica de ninguno de estos dos productos farmacéuticos ${ }^{52}$.

\section{d. OBJECIÓN DE CONCIENCIA A FORMAR PARTE DE UNA MESA ELECTORAL}

Este tipo de objeción ha obtenido carta de naturaleza sólo recientemente y por vía de interpretación administrativa, lo que no había sido hecho por el Tribunal Supremo que, como se adelantó, venía considerando perfectamente ajustada a Derecho sanciones impuestas a Testigos de Jehová por negarse a ese desempeño, basándose en razones de conciencia, negando virtualidad alguna a estos efectos al art. 16.1 de la Carta Magna: "Como tiene dicho esta Sala, formar parte de una mesa electoral permite la más completa neutralidad política, ya que el voto no es obligatorio, limitándose al ejercicio de una actividad canalizadora o de control del voto ajeno. La propia [sentencia] combatida justifica

\footnotetext{
${ }^{50}$ Art. 3.2 de la Ley 7/2001, de 19 diciembre, de Farmacias de Cantabria; art. 5.10 de la Ley 8/1998, de 16 junio, de Farmacia de La Rioja; art. 6 de la Ley 5/1999, de 21 de mayo, de ordenación farmacéutica de la Comunidad Autónoma de Galicia y art. 17 de la Ley 5/2005, de 27 junio, de Farmacia de Castilla-La Mancha.

51 M. ALENDA SALINAS, "La píldora del día después: su conflictividad jurídica...", cit.

52 Vid. Sentencia, del Juzgado de lo Contencioso Administrativo núm. 13 de Sevilla, núm. 257/11, de 2 de noviembre de 2011 (Roj: SJCA 176/2011), dejada sin efecto por el Tribunal Constitucional en su Sentencia de 25 de junio de 2015.
} 
certeramente que todo el mundo es libre para manifestar sus ideas y creencias, lo que no empece al cumplimiento del mandato legal" ${ }^{\prime 53}$.

Esta situación se ha venido produciendo hasta que la Junta Electoral Central dictó la Instrucción 6/2011, de 28 de abril, de interpretación del art. 27.3 de la Ley Orgánica del Régimen Electoral General, sobre impedimentos y excusas justificadas para los cargos de Presidente y Vocal de las Mesas Electorales ${ }^{54}$, considerando que "[s]on causas personales que pueden justificar la excusa del miembro designado de una mesa electoral, atendiendo a las circunstancias de cada caso que corresponde valorar a la Junta Electoral de Zona: La pertenencia a confesiones o comunidades religiosas en las que el ideario o el régimen de clausura resulten contrarios o incompatibles con la participación en una mesa electoral. El interesado deberá acreditar dicha pertenencia y, si no fuera conocido por notoriedad, deberá justificar los motivos de objeción o de incompatibilidad".

\section{e. OTROS SUPUESTOS DE OBJECIÓN DE CONCIENCIA}

No han recibido reconocimiento legal, judicial o administrativo alguno. Los mismos pueden ser muy numerosos en la práctica (y a alguno ya nos hemos referido), por lo que nos limitaremos a aludir a los siguientes: objeción de conciencia fiscal, a la autorización de matrimonios entre personas del mismo sexo, al juramento o promesa, a formar parte de un jurado y otros conflictos de conciencia surgidos en el desempeño de la relación laboral, etc.

\section{A MODO DE CONCLUSIÓN}

Tras este somero repaso al panorama legal y jurisprudencial español, para tratar de salvar las contradicciones, al menos aparentes, en que viene incurriendo el Tribunal Constitucional, es necesario concluir que el mismo maneja dos distintas consideraciones acerca de la objeción de conciencia, que no han dejado de tener su reflejo en la doctrina científica:

Una, la relativa a la fundamentación o posibilidad de raigambre jurídica de la objeción de conciencia, prima facie, en la libertad de creencias garantizada por el art. 16.1 de la CE. Pero ello en cuanto que actuación fáctica del sujeto objetor en íntima vinculación con ese "derecho en germen", sin que el alto Tribunal anude consecuencias jurídicas a esa actitud, al menos en cuanto que ese "derecho" suponga, per se, la facultad de quedar eximido del deber jurídico incumplido por el objetor.

\footnotetext{
53 Sentencia del Tribunal Supremo -Sala II. Sec. 1ạ- de 28 de diciembre de 2007.

54 BOE núm. 103, de 30 de abril de 2011.
} 
A esta caracterización jurídica responden las Sentencias del Tribunal Constitucional 15/1982, 53/1985 y la de 25 de junio de 2015 en la parte que se refiere a la negativa a la expendición de la píldora del día después (y aun así, la primera y la última con matizaciones $)^{55}$.

Esta consideración responde a una evolutiva intelección del derecho a la objeción de conciencia que, de resultar absolutamente extraño en el seno de las Declaraciones Internacionales de derechos humanos, ha llegado a hallar cobijo tanto en el art. 18 del Pacto Internacional de derechos civiles y políticos como en el art. 9 del Convenio Europeo de derechos humanos, al menos por lo que a la objeción de conciencia al servicio militar se refiere $^{56}$. Un paso más decisivo a nivel normativo convencional en la materia es el que viene representado por el art. 10 de la Carta de derechos fundamentales de la Unión Europea que, después de reconocer en su núm. 1 el derecho a la libertad de pensamiento,

55 Ya D. LLAMAZARES FERNÁNDEZ, Derecho Eclesiástico del Estado. Derecho de la Libertad de Conciencia, Servicio Publicaciones Universidad Complutense, Madrid, 1989, p. 624 s., puso de relieve, en su día, que no podía perderse de vista la íntima conexión entre los FFJJ 6 y 7 de la Sentencia del Tribunal Constitucional 15/1982, de modo que extraer del FJ 6 de tal sentencia que la objeción de conciencia al servicio militar constituía un derecho fundamental, constituía una lectura parcial y en contradicción con cuanto se expresaba en el FJ 7 de la misma: ¿Cómo un derecho fundamental puede compaginarse con que haya de ser sometido a un procedimiento administrativo para su declaración?

56 Si bien se analiza, esta distinta regulación jurídica parece ser reflejo de una consideración diversa hacia las concreciones de objeción de conciencia.

No en vano desde diversas instancias internacionales se viene considerando hace ya tiempo que la objeción de conciencia al servicio militar forma parte del derecho a la libertad de pensamiento, conciencia y religión, a pesar de que ni el art. 18 del Pacto Internacional de derechos civiles y políticos ni el art. 9 del Convenio Europeo de derechos humanos hacen referencia explícita a la misma. En este sentido puede traerse a colación diversos pronunciamientos acaecidos tanto en el seno de Naciones Unidas (el Comité de Derechos Humanos al aprobar en 1993 el Comentario General № 22 y las Resoluciones de 10 de marzo de 1993, 8 de marzo de 1995, 22 de abril de 1998, 20 de abril de 2000 y 23 de abril de 2002) como en el ámbito regional europeo (Resolución 337 de 1967 de la Asamblea Consultiva del Consejo de Europa, Resolución de 7 de febrero de 1983 del Parlamento Europeo, etc.). En cambio, mucho más restrictiva se ha mostrado al respecto la Comisión Europea de Derechos Humanos, que ha rechazado la vulneración del art. 9 del Convenio de Roma de 1950 cuantas veces se le ha planteado en temas de objeción a la conscripción obligatoria (v. gr. Decisiones de 17 de mayo y 3 de octubre de 1990, suscitadas por "insumisos" españoles). También por parte del Tribunal Europeo de derechos humanos la interpretación venía siendo contraria a sustentar la objeción de conciencia en el art. 9 del Convenio, sin embargo en la Sentencia dictada por la Gran Sala el 7 de julio de 2011 (caso Bayatyan contra Armenia), se ha reconocido por primera vez que el derecho a la objeción de conciencia al servicio militar se encuentra íntimamente ligado al derecho a la libertad de creencias. Vid. F.J. RUIZ BURSÓN, "Novedades desde Estrasburgo sobre la objeción de conciencia", en Revista General de Derecho Canónico y Derecho Eclesiástico del Estado, 31 (2013). Y ello en contraste con la Sentencia de 27 de octubre de 2009, que deja sin efecto. Vid. nuestro trabajo "El Tribunal de Derechos Humanos ante la objeción de conciencia al servicio militar: ¿̇nmovilismo o falta de cobertura legal?”, en la misma Revista acabada de citar del Portal Jurídico lustel.com, núm. 22 (2010). 
de conciencia y de religión, añade en su núm. 2: "Se reconoce el derecho a la objeción de conciencia de acuerdo con las leyes nacionales que regulen su ejercicio".

Otra, que la objeción de conciencia, por muy vinculada que esté al art. 16.1 de la CE, sea constitutiva de un derecho a la exención del cumplimiento de deberes constitucionales o legales.

A este tipo de impronta responde el grueso de resoluciones que hemos referido del Tribunal Constitucional ${ }^{57}$, ampliamente seguidas por el Tribunal Supremo, que exigen la "juridificación" de la objeción de conciencia para que la misma pueda tener ese alcance liberador del cumplimiento del deber jurídicamente exigible.

La diferencia entre ambas consideraciones relativas a la objeción de conciencia es que, en el primer caso, y en cuanto que posibilidad primigenia de surgimiento del derecho no es necesaria la interpositicio legislatoris; mientras que para que ese derecho se constituya, por sí solo, en legítima exención del cumplimiento de un deber jurídicamente establecido sí que se necesita la "habilitación" al efecto del legislador: la mayor de las veces en forma explícita y, aunque excepcionalmente, de forma implícita, a tenor de la interpretación que del supuesto concreto hayan de hacer los Tribunales de Justicia. Para estos últimos casos, la aceptación de la objeción de conciencia en forma de tipificación social habrá de ser tal, que el aplicador del Derecho estime que se debiera haber procedido a su tipificación legislativa.

\footnotetext{
57 También la Sentencia del Tribunal Constitucional de 25 de junio de 2015, por lo que se refiere a la objeción de conciencia a la negativa al almacenamiento y disposición de profilácticos y, en parte, a la que alcanza al rehúse de la píldora postcoital.
} 